\title{
Competition in the Family: Inequality between Siblings and the Intergenerational Transmission of Educational Advantage
}

\author{
Michael Grätz
}

University of Oxford; Bielefeld University

Abstract: Research on educational mobility is concerned with inequalities between families. Differences in innate abilities and parental responses lead, however, to educational differences between siblings. If parental responses vary by family socioeconomic background, within-family inequality can affect between-family inequality (i.e., educational mobility). This study uses data from the German Socio-Economic Panel Study (SOEP) to test whether sibling similarity in education varies by family socioeconomic background. In addition, I test whether the effects of birth order, birth spacing, and maternal age on education vary by family background. Results show that sibling similarity in education is similar in low- and high-socioeconomic status families. The negative influences of a higher birth order and a younger maternal age on educational attainment, however, are concentrated in socioeconomically disadvantaged families. These findings suggest that socioeconomically advantaged families do not generally compensate for ability differences between their children but that they compensate for disadvantageous life events.

Keywords: educational inequality; intergenerational transmission; siblings; social mobility

Citation: Grätz, Michael. 2018. "Competition in the Family: Inequality between Siblings and the Intergenerational Transmission of Educational Advantage." Sociological Science 5: 246269.

Received: December 19, 2017

Accepted: April 2, 2018

Published: May 17, 2018

Editor(s): Jesper Sørensen, Stephen Morgan

DOI: $10.15195 /$ v5.a11

Copyright: (C) 2018 The Author(s). This open-access article has been published under a Creative Commons Attribution License, which allows unrestricted use, distribution and reproduction, in any form, as long as the original author and source have been credited. (0)(1) central topic of research on social stratification is the transmission of educaA tional advantage across generations (Breen and Jonsson 2005). This research focuses on differences between children belonging to different families. Less attention is paid to inequalities in education that arise between siblings. A popular approach to estimate the total effect of family background on child education (i.e., educational mobility) is to measure sibling similarity in education (Björklund and Jäntti 2012; Jencks et al. 1972). This approach allows researchers to estimate the total impact of family background on education as sibling correlations take into account both observed and unobserved aspects of family background. Research employing this approach usually finds that about half of the variation in education is due to variation between families. This result implies, vice versa, that the other half of educational inequality is produced within families. This fact is seldom acknowledged by stratification research. In order to fully understand how educational inequalities are produced, research on social stratification has, however, to explain why siblings diverge in their educational outcomes.

What is more, there may be interactions between within- and between-family inequality that are not taken into account by research that ignores within-family inequality. A large literature in economics and sociology discusses that parents invest resources unequally among their offspring. Becker and Tomes' (1976) classical model of resource allocation within families predicted that parents reinforced ability differences between their children with respect to their human capital (and 
compensated via direct transfers). Contrary to that, Behrman, Pollak, and Taubman (1982) developed a model in which parents, who have equity concerns, responded with compensatory investments to ability differences between siblings. As Griliches (1979) and Conley $(2004,2008)$ speculated, these processes may differ by family socioeconomic background. If reinforcing parental responses are stronger in highthan in low-socioeconomic status families, sibling similarity in education is likely to be lower in high- than in low-socioeconomic status families. If, however, compensatory parental investment strategies are more pronounced in socioeconomically advantaged families, these families are likely to have offspring who are more similar in their educational outcomes than siblings coming from socioeconomically disadvantaged families.

Notwithstanding these theoretical reasons to expect the effects of within-family inequality to affect educational mobility, research that examines empirically how differences between siblings are brought about and how processes of within-family inequality differ by family socioeconomic background is rare. Empirical evidence on the variation of sibling similarity by family socioeconomic background is limited to the United States and focused more on socioeconomic status as an outcome than on education (Conley 2008; Conley and Glauber 2008; Conley, Pfeiffer, and Velez 2007). This research gap is a major shortcoming because if indeed sibling similarity varies by family socioeconomic background, estimates of educational mobility, which do not take into account the effects of within-family inequality, are misleading.

This study tests in two ways the importance of within-family inequality for the process of educational mobility using data on Germany from the Socio-Economic Panel Study (SOEP). First, I test whether sibling similarity in education varies by family socioeconomic background. This is the first study to analyze this research question using data on a country other than the United States. ${ }^{1}$ Differences in educational and labor market institutions may lead to differences in the variation of within-family inequalities across countries. For that reason, it is important to expand this research to other contexts than the United States. Germany, a country characterized by high educational inequalities (Björklund and Salvanes 2011; Pfeffer 2008; Shavit and Blossfeld 1993) and a conservative welfare state (Esping-Andersen 1990), provides an important case study. Second, I test whether the impact of sibling characteristics (birth order, birth spacing, and maternal age) on children's educational outcomes varies by family socioeconomic background. Previous research argued that birth order, birth spacing, and maternal age affect children's educational outcomes. To the best of my knowledge, however, this is the first study to focus on analyzing whether the impact of these sibling characteristics on education varies by family socioeconomic background using family fixed-effects models and, hence, to test whether these sibling characteristics affect the intergenerational transmission of educational advantage. ${ }^{2}$ 


\section{Family Socioeconomic Background and Sibling Differences in Education}

\section{Sibling Similarity and Differences in Education}

Both in sociology and in economics, there is a large literature that uses sibling similarity in education as a measure of how much family background influences child education. The advantage of this method, compared to measuring educational mobility through the association between parental and child education, is that it takes into account both observed and unobserved aspects of family background (Björklund and Jäntti 2012). Studies analyzing the United States demonstrate that about half of the variation in education can be explained between families (Benin and Johnson 1984; Duncan, Boisjoly, and Harris 2001; Hauser and Mossel 1985; Hauser and Wong 1989; Jencks et al. 1972; Kuo and Hauser 1995; Mazumder 2008; Teachman 1995). Some studies apply this approach to Europe and obtain similar estimates of sibling similarity in education in various European countries (Björklund and Jäntti 2012; de Graaf and Huinink 1992; Nicoletti and Rabe 2013; Olneck 1977; Schnitzlein 2014; Sieben and de Graaf 2001, 2003; Sieben, Huinink, and de Graaf 2001; Toka and Dronkers 1996).

Although this research is usually understood as pointing to the importance of family background for children's educational outcomes, a further implication of findings from these studies is that siblings differ substantially in their educational outcomes. If half of the variation in education is produced between families, this implies that the other half is produced within families. For that reason, research on educational inequality should not only analyze inequalities in education between families but also inequalities between siblings.

\section{Variation of Sibling Similarity in Education by Family Socioeconomic Background}

Sibling correlations in educational outcomes are often understood as lower-bound estimates of the total impact of family background on child education because factors transmitted from parents to children, which are not completely shared among siblings, are not taken into account by sibling correlations (Björklund and Jäntti 2012). What is more, if the influence of sibling-specific factors varies by family socioeconomic background, sibling correlations may be biased estimates of the total effect of family background on child education (Conley 2008). Research has, therefore, to test whether sibling similarity in education varies by family socioeconomic background.

Parental investment strategies may lead to variation in sibling similarity across social origin groups. Models of resource allocation within families predict that parents either invest similarly in the human capital of all children, invest more in the sibling with the higher endowments in order to maximize the returns on their investments (Becker 1991; Becker and Tomes 1976), or invest more in the less able sibling, aiming, hence, at compensating for ability differences between their children (Behrman et al. 1982; Griliches 1979). 
Which of these strategies families employ is likely to be a function of the resources available to parents (Conley 2004, 2008; Griliches 1979). The first possibility is that all families aim at reinforcing ability differences between siblings but budget constraints result in socioeconomically disadvantaged families being unable to implement reinforcing strategies (Becker 1991; Becker and Tomes 1976). Contrary to that, socioeconomically advantaged families, who do not face budget constraints, are reinforcing ability differences and compensate via direct transfers to the disadvantaged sibling. As a consequence, this theory leads us to expect sibling similarity to decrease with increasing socioeconomic status.

If parents, however, are mainly motivated by equalizing concerns, we expect the opposite relationship between family background and sibling similarity. Compensatory strategies are more feasible for families with many resources (Griliches 1979). Therefore, socioeconomically advantaged families may compensate for ability differences between their children, whereas socioeconomically disadvantaged families, under budget constraints, rather reinforce ability differences or have a child ability-neutral investment pattern (Conley 2004, 2008). As a result, siblings from higher-social origin families should resemble each other in their educational outcomes more than siblings from lower-social origin families.

Finally, the third possibility is that parental investment strategies do not vary by family socioeconomic background. If this is the case, sibling correlations should be similar across social origin groups. Although this assumption is usually not explicitly stated, it is underlying the standard approach to the study of intergenerational educational mobility, which does not take into account within-family inequality.

These three competing hypotheses have to be tested empirically. So far, empirical evidence is only available for the United States. Qualitative evidence supporting the notion of a higher sibling similarity in socioeconomically advantaged families was offered by Conley (2004). Conley et al. (2007) found no evidence for socioeconomic differences in sibling similarity by maternal education with respect to cognitive skills. However, they found children with less educated mothers to be more similar in behavioral problems than children with highly educated mothers. Using data on Germany, Anger and Schnitzlein (2017) also found a slightly higher sibling similarity in noncognitive skills in families with a high level of family income or maternal education than in families with a low level of family income or maternal education. Conley and Glauber (2008), using data from the United States' Panel Study of Income Dynamics (PSID), found lower sibling similarity in years of education for families with a low income and for families with a large family size. They interpreted these findings as evidence in favor of compensation in socioeconomically advantaged families. However, they did not find significant differences between families with a low and a high level of parental education. Similarly, Conley (2008) found no differences in sibling similarity in education by maternal education in the United States.

In addition, research that directly tested parental responses to children's early abilities found mixed results with respect to socioeconomic heterogeneity in these responses. Both Hsin (2012) and Restrepo (2016) analyzed whether parental responses to birth weight differences between siblings varied by parental education in the United States. Both studies came to the conclusion that families with a low 
level of parental education invested more in children with a higher birth weight, whereas families with a high level of parental education invested more in children with a lower birth weight. Grätz and Torche (2016), however, found no evidence for this dynamic when analyzing parental responses to birth weight differences between twins in the United States. In addition, they found, contrary to Griliches' (1979) and Conley's $(2004,2008)$ prediction, a concentration of reinforcing responses to twin differences in early abilities in high-socioeconomic status families.

To sum up, results from previous research suggest that sibling similarity in education may vary by family socioeconomic background. However, those studies that focused on the underlying mechanism, socioeconomic differences in parental responses to differences in early abilities or birth endowments between siblings, produced inconsistent results. Results from Grätz and Torche (2016) are in line with Becker and Tomes' (1976) original model and would lead us to expect a lower sibling similarity in socioeconomically advantaged families. Hsin (2012) and Restrepo (2016), however, found, supporting Griliches (1979) and Conley $(2004,2008)$, evidence for compensatory responses in socioeconomically advantaged families that should result in higher levels of sibling similarity in these families. These different predictions derived from results of previous research underline the importance of testing empirically whether sibling similarity varies by family socioeconomic background.

What is more, research on the variation of sibling similarity in education has so far been limited to the United States. There may, however, be cross-national differences in the socioeconomic variation of sibling similarity in education. In particular, different educational and economic institutions and welfare states may affect how much parental responses can affect within-family inequality. For that reason, it is important to expand analyses of socioeconomic differences in withinfamily inequality to countries other than the United States. This study uses data on Germany, a conservative welfare state with early tracking in the education system. Whereas similar overall levels of educational inequality between Germany and the United States suggest that a similar relation of within- and between-family components could be underlying educational inequality, an alternative hypothesis postulates that within-family inequalities are less pronounced in Germany than in the United States. This may be the case if the rigid German education system gives parents fewer possibilities to influence the long-term consequences of sibling differences. For that reason, compensatory or reinforcing parental responses to ability differences between or disadvantageous life events occurring differently to siblings may have less of an effect on children's further educational careers in Germany. As a result, there may be a weaker variation of sibling similarity by family socioeconomic background in Germany than in the United States.

\section{Variation of the Impact of Sibling Characteristics on Education by Family Background}

The discussion in the previous section focused on the variation of sibling similarity in education across social origin groups. A second task is to explain how this variation in sibling similarity is produced. Socioeconomic differences in sibling 
similarity could be produced if parental responses to sibling characteristics, which influence child development, vary by family background and if these parental responses lead to socioeconomic differences in the effects of sibling characteristics on education. This section discusses three sibling characteristics (birth order, birth spacing, and maternal age at birth) and why the impact of these characteristics on children's educational outcomes may vary by family socioeconomic background. Previous research has argued that the incidence of disadvantageous life events, such as a young maternal age, can vary by family background (e.g., McLanahan 2004). My analysis tests, however, whether the effects of these life events on educational outcomes vary by family background.

Support for the perspective that the effects of sibling characteristics vary by family background comes from the literature on the effects of prenatal and early health conditions on long-term outcomes (Almond and Mazumder 2013). This literature argues that parents respond to health endowments at birth, with consequences for children's educational and occupational outcomes. For instance, Almond, Edlund, and Palme (2009) used regional variation in Sweden in the prenatal exposure to radiation following the Chernobyl accident in order to analyze the effects of health endowments on children's cognitive development. They found that a higher radiation negatively influenced children's cognitive skills, with the negative effect being concentrated in families in which the father had a low level of education. Bernardi (2014) showed that the negative effect of a young school entry age on grade retention in France was concentrated in lower-class families. Bernardi and Grätz (2015) found, using data on children's educational performance in England, a negative effect of a young school entry age on educational performance at school start for both children with less educated and children with highly educated parents. For the latter group, however, the negative influence of a young school entry age disappeared over the school career. Using data on Germany, Grätz (2015) demonstrated that parental separation negatively affected children's educational outcomes only in families with a low level of parental education. Ermisch and Francesconi (2013) found that maternal employment during young childhood had negative effects on the educational outcomes of children from less educated mothers but no negative effects on the education of children from highly educated mothers. Similarly, Torche and Echevarría (2011) reported that the negative effect of a low birth weight on cognitive development was concentrated in families with less educated mothers. In addition, Aizer, Stroud, and Buka (2016) found that children with less educated mothers were more negatively affected by exposure to maternal stress in utero than children with highly educated mothers. My study contributes to this literature by analyzing socioeconomic heterogeneity in the effects of birth order, birth spacing, and maternal age on children's educational outcomes.

Birth order. A number of studies found negative causal effects of a higher birth order on children's cognitive skills and educational outcomes (e.g., Barclay 2015a, 2015b; Bjerkedal et al. 2007; Black, Devereux, and Salvanes 2005; Booth and Kee 2009; Kantarevic and Mechoulan 2006; Kristensen and Bjerkedal 2007, 2010). In line with these results, previous research also found negative associations between birth order and educational outcomes in Germany (Karwath, Relikowski, and Schmitt 2015; Schulze and Preisendörfer 2013; Stoye 2016). In addition, Härkönen (2014) and 
Stoye (2016) used family fixed-effects models to estimate birth order effects within families in Germany. For instance, Härkönen (2014) reported that the probability of graduating from the highest educational track (Gymnasium) in the German education system was around 4 percentage points lower for second-born children than for first borns.

The focus of my study is on whether the effect of birth order on education varies by family socioeconomic background. In so far as the negative effect of a higher birth order on education occurs through financial resource limitations, I expect this effect to be more pronounced in socioeconomically disadvantaged families. It could, however, be that parental time restrictions bring about the birth order effect (Price 2008). In this case, children from lower- and higher-social origin families should equally be affected, and hence, the effect of birth order on education should not vary by family socioeconomic background.

Previous research produced mixed evidence on socioeconomic differences in the effect of birth order on education. Barclay (2015b) found, using family fixed-effects models and data on Sweden, no socioeconomic differences in the effect of birth order on intelligence among brothers. Contrary to that, Karwath et al. (2015) found, using data on a small region in Germany and not employing family fixed-effects models, a negative association between a higher birth order and vocabulary skills for children from less educated families but not for children from highly educated families. With respect to educational attainment, previous research based on withinfamily variation found no differences in birth order effects by maternal education in Norway (Black et al. 2005) or by parental occupational status and education in Germany (Härkönen 2014). A difference between these two studies and mine is that they did not test whether the effect of birth order varied by family background simultaneously with the effects of birth spacing and maternal age.

Birth spacing. Powell and Steelman $(1990,1993)$ argued that having more closely spaced siblings was detrimental to educational outcomes in the United States. Contrary to that, using data on Hungary, van Eijck and de Graaf (1995) found a positive instead of a negative effect of having a closely spaced sibling on educational outcomes. One difference between their study and Powell and Steelman's (1990, 1993) work is that they used an interval of six years to define closely spaced siblings instead of a two-year interval. Using exogenous variation in child spacing due to a Swedish reform, Pettersson-Lidbom and Skogman Thoursie (2009) estimated close birth spacing to have negative consequences for university attendance. Using miscarriages between live births as an instrumental variable for birth spacing and data on the United States, Buckles and Munnich (2012) supported the notion that close birth spacing has a negative effect on educational performance. Contrary to that, Barclay and Kolk (2017), applying family fixed-effects models to Swedish register data, found no negative effect of birth spacing on education.

These studies did not investigate whether the negative effect of having more closely spaced siblings on education varied by family socioeconomic background. If, however, the dilution of parental resources is the main mechanism underlying the negative effect of having more closely spaced siblings on educational outcomes, as argued by Powell and Steelman (1995), I expect the negative effect of having 
more closely spaced siblings on educational outcomes to be more pronounced in socioeconomically disadvantaged families.

Maternal age. Previous research found evidence for positive associations between higher maternal and paternal ages and children's educational outcomes. For instance, Mare and Tzeng (1989) reported a positive association between a higher paternal age and educational attainment of sons in the United States. Using data on the Netherlands, Kalmijn and Kraaykamp (2005) demonstrated that the positive effects of higher maternal and paternal ages on years of education were also brought about using family fixed-effects models. Similarly, Barclay and Mysrkylä (2016) found positive effects of higher maternal and paternal ages on education using family fixed-effects models and data from Sweden.

These studies did not test whether the positive effect of a higher maternal age on education varied by family socioeconomic background. The underlying mechanism of the maternal age effect may be, as argued by Kalmijn and Kraaykamp (2005), an increase in mothers' (and/or fathers') skills over the life course. In line with this hypothesis, Powell, Steelman, and Carini (2006) showed that a higher parental age was associated with the transmission of more economic, cultural, and social resources to the child. The negative effect of a young maternal age may be more pronounced in socioeconomically disadvantaged families for two reasons. First, young mothers and fathers from these families may have particularly few skills and resources. They may, therefore, accumulate relatively more skills and resources over the life course than parents from socioeconomically advantaged families. Second, skills and resources may have fewer consequences for children's educational outcomes in socioeconomically advantaged families as they are more likely to be able to compensate for the lack of skills and resources of one type due to a young maternal age through skills and resources of other types (Erola and Kilpi-Jakonen 2017).

\section{Data and Methods}

\section{Data and Sample Selection}

The analysis in this article uses data on a sample of 2,924 siblings from 1,313 families, derived from the German Socio-Economic Panel Study (version 32.1; SOEP 2017). The SOEP is a long-running panel study that samples household units (Wagner, Frick, and Schupp 2007). The study started in 1984 with a sample of West German households and includes a sample of East German households since 1991. Because all household members are sampled and observed after they leave their initial households, a sample of siblings born into the same households can be constructed.

The sample is restricted to respondents who filled out a special questionnaire in the year in which they turned 17, providing information on educational outcomes in the year preceding the survey (i.e., when they were usually 16 years old). The sample includes respondents born between 1982 and 1998. Respondents without any sibling with valid information on the variables included in the analysis are dropped from the analyzed sample. In addition, I dropped children from the sample who experienced the death of one of their parents during childhood. 


\section{Variables}

I use two measures of educational outcomes: a measure of cognitive skills and a dichotomous variable that indicates whether someone attends the highest track in secondary school (Gymnasium) leading to Abitur (a high school degree that is required to access university, comparable to A-Levels in the United Kingdom).

Cognitive skills. The measure of cognitive skills is based on a cognitive skills test included in the survey since 2006. The aim of this test is to measure fluid cognitive skills. The three parts of the test measure the ability to perform word analogies, numeric cognitive potential, and figural cognitive potential. A detailed account of the questions used to measure these three components is provided in Schupp and Herrmann (2009). I use a measure of all correct answers in all three parts of the test as an outcome variable. I standardize this variable to have a mean of 0 and a standard deviation of 1 . Because this test was only conducted from 2006 onwards, the analysis sample of this outcome is restricted to respondents born between 1987 and 1998.

Upper track attendance. Research has argued that early tracking, which happens when children are 10 to 12 years old, is the main reason for high inequality in educational outcomes in Germany (Hillmert and Jacob 2010). Consequently, attendance of the upper track can be used as a proxy for final educational attainment. Upper track attendance is a dichotomous variable, which is coded 1 for all respondents who attend the highest track in the German education system at age 16 to 17 years and 0 for all other respondents. This latter group includes high school dropouts and those who attend lower tracks. Respondents who attend so-called comprehensive schools (Gemeinschaftsschulen), which combine all tracks into one school, are dropped from the analysis of this outcome. Because this is the case for only 195 children, it seems unlikely that this reduction in the analyzed sample induces any bias.

Sibling characteristics. In the second part of the analysis, I use family fixed-effects models in order to estimate the impact of birth order, birth spacing, and maternal age on education. Birth order is a continuous variable, which gives the rank within the sibling group. Birth spacing is coded by counting the number of siblings born within an interval of two years around a respondent's birth year. In other words, this variable counts the number of siblings born the previous, the same, or the year after the respondent. Maternal age is a continuous variable, reporting maternal age at birth.

Family socioeconomic background. I use three separate indicators of family socioeconomic background. Parental education is measured by the highest level of education achieved by either parent. I employ a dummy variable, which is coded 1 if one or both parents have an Abitur degree (or an equivalent qualification) and 0 otherwise. Parental occupational status is a continuous variable measured via the International Socio-Economic Index (ISEI) (Ganzeboom, de Graaf, and Treiman 1992). In order to compare two groups, I assign children who have a parental ISEI score higher than 70 as being from families with a high parental occupational status and those with a score of 70 or lower as being from families with a low parental occupational status. High parental social class is defined as a dummy variable, which is set to 1 if one of the parents belongs to the highest social class (Erickson, Goldthorpe, Portocarero [EGP] I; i.e., is a higher-grade professional or 
is self-employed with employees [EGP IVa]) as defined in the EGP class schema. The dummy variable is set to 0 if none of the parents holds an occupation in one of these categories.

Migration background. In one part of the analysis, I analyze sibling correlations separately by migration background. Someone is defined as having a migration background if both parents were born outside Germany.

Control variables. I control in all models for gender with a dummy variable, which is coded 1 for male respondents.

Descriptive statistics on the sample used in the analysis are reported in Table 1. These statistics include decompositions of the variances into between- and withinfamily components. These decompositions demonstrate that although most of the variation in birth order, birth spacing, and maternal age is between families, there is also considerable variation in terms of these variables within families.

In addition to descriptive statistics on the full sample, Table 1 reports descriptive statistics with respect to subsamples of children with highly and low educated parents. One concern with respect to the family fixed-effects models may be that the amount of variation available to identify the effects of birth order, birth spacing, and maternal age may vary across social groups. In particular, if indeed the incidence of these sibling characteristics varies by family background, a statistical concern is that there may not be enough variation in highly educated families to identify the effects of birth order, birth spacing, and maternal age in family fixed-effects models. The comparison of the variation in these variables between low and highly educated families shows, however, that this concern is unfounded. There is similar variation with respect to birth order, birth spacing, and maternal age in both the sample of children with low educated and the sample of children with highly educated parents. For that reason, differences in the effects of birth order, birth spacing, and maternal age in the family fixed-effects models reported below point to true underlying differences in the effects of birth order, birth spacing, and maternal age across social groups and not just at socioeconomic variation in the incidence of birth order, birth spacing, and maternal age differences within families.

\section{Analytical Strategy}

In order to achieve the two aims of this study, I employ two techniques. First, I use multilevel models to test whether sibling similarity in education varies by family socioeconomic background. Second, I employ family fixed-effects models to test whether the impact of birth order, birth spacing, and maternal age on education varies across social origin groups.

Sibling similarity in education is estimated through measures of sibling correlations in cognitive skills and track attendance. More precisely, I estimate restricted maximum likelihood (REML) multilevel models and use the intraclass correlation coefficients (ICCs) of these models as measures of sibling similarity (Björklund and Jäntti 2012; Mazumder 2008; Schnitzlein 2014). The analysis of multilevel models restricted to specific social origin groups tests whether sibling similarity varies by family socioeconomic background (Conley 2008; Conley et al. 2007; Conley and Glauber 2008). 
Table 1: Descriptive statistics.

\begin{tabular}{|c|c|c|c|c|c|}
\hline & Mean & $\mathrm{SD}$ & $\mathrm{SD}_{\text {between }}$ & $\mathrm{SD}_{\text {within }}$ & $N$ \\
\hline \multicolumn{6}{|l|}{ Panel A: Full sample } \\
\hline Number of children per family & 2.35 & 0.66 & - & - & 2,924 \\
\hline Age in 2015 & 24.19 & 4.58 & 4.16 & 2.08 & 2,924 \\
\hline Cognitive skills & 0.00 & 1.00 & 0.91 & 0.50 & 1,327 \\
\hline Upper track attendance (Gymnasium) & 0.45 & 0.50 & 0.44 & 0.25 & 2,671 \\
\hline High parental education & 0.36 & 0.48 & - & - & 2,924 \\
\hline High parental occupational status (ISEI) & 0.06 & 0.24 & - & - & 2,924 \\
\hline High parental social class & 0.21 & 0.40 & - & - & 2,924 \\
\hline Migration background & 0.24 & 0.43 & - & - & 2,924 \\
\hline Male & 0.50 & 0.50 & 0.35 & 0.36 & 2,924 \\
\hline Birth order & 1.88 & 0.93 & 0.62 & 0.65 & 2,924 \\
\hline Number of closely spaced siblings & 0.25 & 0.47 & 0.42 & 0.19 & 2,924 \\
\hline Maternal age & 27.79 & 4.82 & 4.37 & 2.08 & 2,924 \\
\hline \multicolumn{6}{|l|}{ Panel B: High parental education } \\
\hline Number of children per family & 2.37 & 0.68 & - & - & 1,057 \\
\hline Age in 2015 & 23.28 & 4.44 & 4.02 & 1.99 & 1,057 \\
\hline Cognitive skills & 0.37 & 0.90 & 0.78 & 0.50 & 490 \\
\hline Upper track attendance (Gymnasium) & 0.73 & 0.44 & 0.38 & 0.24 & 976 \\
\hline High parental education & 1.00 & 0.00 & - & - & 1,057 \\
\hline High parental occupational status (ISEI) & 0.15 & 0.36 & - & - & 1,057 \\
\hline High parental social class & 0.41 & 0.49 & - & - & 1,057 \\
\hline Migration background & 0.13 & 0.34 & - & - & 1,057 \\
\hline Male & 0.52 & 0.50 & 0.35 & 0.36 & 1,057 \\
\hline Birth order & 1.83 & 0.84 & 0.48 & 0.66 & 1,057 \\
\hline Number of closely spaced siblings & 0.26 & 0.48 & 0.43 & 0.19 & 1,057 \\
\hline Maternal age & 29.86 & 4.35 & 3.92 & 1.99 & 1,057 \\
\hline \multicolumn{6}{|l|}{ Panel C: Low parental education } \\
\hline Number of children per family & 2.34 & 0.65 & - & - & 1,867 \\
\hline Age in 2015 & 24.70 & 4.58 & 4.14 & 2.12 & 1,867 \\
\hline Cognitive skills & -0.22 & 0.99 & 0.91 & 0.50 & 837 \\
\hline Upper track attendance (Gymnasium) & 0.28 & 0.45 & 0.38 & 0.26 & 1,695 \\
\hline High parental education & 0.00 & 0.00 & - & - & 1,867 \\
\hline High parental occupational status (ISEI) & 0.01 & 0.10 & - & - & 1,867 \\
\hline High parental social class & 0.09 & 0.29 & - & - & 1,867 \\
\hline Migration background & 0.30 & 0.46 & - & - & 1,867 \\
\hline Male & 0.50 & 0.50 & 0.35 & 0.37 & 1,867 \\
\hline Birth order & 1.91 & 0.98 & 0.68 & 0.65 & 1,867 \\
\hline Number of closely spaced siblings & 0.24 & 0.46 & 0.41 & 0.19 & 1,867 \\
\hline Maternal age & 26.61 & 4.68 & 4.15 & 2.13 & 1,867 \\
\hline
\end{tabular}

Source: German Socio-Economic Panel Study (SOEP) version 32.1 (DOI: 10.5684/soepv32.1). 
In the multilevel models, I only control for gender. Hence, these models can be written as (cf. Schnitzlein 2014)

$$
E_{i j}=X_{i j} \beta+\alpha_{i}+\delta_{i j}
$$

with $\mathrm{E}_{i j}$ being the educational outcome of interest, $\mathrm{X}_{i j}$ being the gender control, $\alpha_{i}$ being the family-specific component, and $\delta_{i j}$ being the individual-specific component.

From these models, I report and compare the intraclass correlation coefficients $\rho$

$$
\rho=\sigma_{\alpha}^{2} /\left(\sigma_{\alpha}^{2}+\sigma_{\delta}^{2}\right),
$$

with $\sigma_{\alpha}^{2}$ being the variance of the family-specific component and $\sigma_{\delta}^{2}$ being the variance of the individual-specific component. Hence, the ratio $\rho$ reports how much of the total variance $\sigma_{\alpha}^{2}+\sigma_{\delta}^{2}$ is shared by siblings. To give an example from previous research, Schnitzlein (2014) reports an intraclass correlation $\rho$ in earnings of 0.43 for brothers and 0.39 for sisters in Germany. The multilevel models are estimated using the xtmixed command in Stata 14.2.

The impact of sibling characteristics is estimated using family fixed-effects models. Family fixed-effects models are similar to individual fixed-effects models with the difference being that the outcomes of an individual are compared not over several time points but to siblings who have grown up in the same family.

The idea behind the family fixed-effects models is to estimate differences between siblings (cf. Conley et al. 2007)

$$
E_{i k}-E_{i l}=\left(X_{i k}-X_{i l}\right) \beta+\left(\alpha_{i}-\alpha_{i}\right)+\left(\delta_{i k}-\delta_{i l}\right),
$$

with $E$ being the educational outcome of interest, the subscript $i$ referring to the family with $k$ and $l$ referring to two siblings from that family. $X$ is a vector of explanatory variables (in this study, birth order, birth spacing, maternal age, and gender). ${ }^{3}$ The error component of this model consists of a family-specific error term and an individual-specific error term. The model controls for the family-specific error term. The estimated models in the analysis allow for the fact that there can be more than two siblings in each family and that the number of siblings per family varies. In families with more than two children, the information on all siblings is taken into account.

Not only does employing family fixed-effects models allow me to control for unobserved heterogeneity, it is also the only approach that makes it possible to analyze how inequalities within families occur. Only differences between siblings of the same family contribute to the estimates of the effects of birth order, birth spacing, and maternal age. I interact the measures of birth order, birth spacing, and maternal age with parental education in order to test whether the influences of birth order, birth spacing, and maternal age on education vary by family socioeconomic background.

There are limitations in the application of family fixed-effects models. Frisell et al. (2012) discuss that the omission of variables that vary between siblings and measurement error can lead to bias in family fixed-effects models. It is, hence, important to control for factors that vary between siblings, such as gender. There 
may still be bias through confounding variables that leads to differences in educational outcomes between siblings but are not included as control variables. There is, however, little research on which control variables need to be applied in family fixed-effects models and how they correlate with birth order, birth spacing, and maternal age. For that reason, I do not expect any remaining bias to be very large in size. The problem of measurement error is reduced in this study by using data from a high-quality panel study. In addition, reverse causality could be a problem in the sense that these models do not take into account parental fertility responses to children's endowments (Ermisch and Francesconi 2013). Similar to the case of control variables in family fixed-effects models, this is a topic on which more empirical research is needed. I am not able to do this in this study and assume that any effect of reverse causality is small. In any case, we should be aware that causal interpretations of the family fixed-effects models rest on two assumptions: first, all confounding variables that vary between siblings are controlled for, and second, there is no reverse causality in the sense that children's endowments influence parental fertility decisions.

Cognitive skills are measured as a standardized continuous variable, and the effects of sibling characteristics on cognitive skills are, therefore, estimated by using ordinary least squares (OLS) regression models with fixed effects. Upper track attendance is a dichotomous outcome variable that is estimated by using linear probability models with fixed effects. The use of linear probability models allows me an easy interpretation of regression coefficients; in particular, it makes it possible to interpret the interaction effects between sibling characteristics and parental education (Mood 2010). Family fixed-effects models are estimated using the xtreg command in Stata 14.2.

\section{Results}

\section{The Stratification of Sibling Similarity in Education}

Table 2 reports estimates of sibling similarity in education. The first row reports the total effect of family background on cognitive skills and track attendance. These results suggest that educational mobility varies in Germany between 0.42 (cognitive skills) and 0.51 (upper track attendance).

The estimates reported in the other rows test the stratification of sibling similarity in education. Three indicators of family socioeconomic background are used: parental education, parental occupational status (ISEI), and parental social class. Independent of which of these variables is used, sibling similarity in education is very similar between low- and high-social origin groups. For instance, for respondents from families with a high level of parental education, sibling similarity is 0.36 in cognitive skills and 0.44 in track attendance. In families with a low level of parental education, these estimates are 0.37 (cognitive skills) and 0.38 (upper track attendance) and, hence, nearly identical as well. Results for occupational status and social class are virtually identical. There are, therefore, no differences in sibling similarity in education by family socioeconomic background. 
Table 2: Sibling correlations in educational outcomes.

\begin{tabular}{lcc}
\hline & & $\begin{array}{c}\text { Upper track } \\
\text { attendance } \\
\text { (Gymnasium) }\end{array}$ \\
\hline Full sample & $\begin{array}{c}\text { Cognitive } \\
\text { skills }\end{array}$ & 0.51 \\
& 0.42 & $(0.02)$ \\
High parental education & $(0.03)$ & 0.44 \\
& 0.36 & $(0.04)$ \\
Low parental education & $(0.06)$ & 0.38 \\
& 0.37 & $(0.03)$ \\
High parental occupational status (ISEI) & $(0.05)$ & 0.52 \\
& 0.46 & $(0.08)$ \\
Low parental occupational status (ISEI) & $(0.15)$ & 0.49 \\
& 0.42 & $(0.02)$ \\
High parental social class & $(0.04)$ & 0.47 \\
& 0.37 & $(0.05)$ \\
Low parental social class & $(0.08)$ & 0.48 \\
& 0.41 & $(0.02)$ \\
No migration background & $(0.04)$ & 0.50 \\
& 0.37 & $(0.02)$ \\
Migration background & $(0.04)$ & 0.51 \\
& 0.39 & $(0.04)$ \\
\hline
\end{tabular}

Notes: The table reports the intraclass correlation coefficients of multilevel models estimated with restricted maximum likelihood (REML). Standard errors are in parentheses. Source: German Socio-Economic Panel Study (SOEP) version 32.1 (DOI: 10.5684/soepv32.1).

One further difference may arise between families with and without a migration background. Comparing these two groups, sibling correlations are nearly identical. For respondents without a migration background, sibling similarity is 0.37 in cognitive skills and 0.50 in track attendance. Sibling correlations in families with a migration background are 0.39 in cognitive skills and 0.51 in upper track attendance. To sum up, the analysis provides no support for a stratification of sibling similarity in educational outcomes. Contrary to the theoretical expectations, sibling similarity in education is similar in socioeconomically advantaged and disadvantaged families.

\section{Variation of the Impact of Sibling Characteristics on Education}

Sibling correlations are informative. But if inequality between siblings is largely caused by locating one social origin group at the upper end of an outcome variable and another group at the lower end, sibling correlations within these groups can be of a similar size, whereas at the same time, the meaning and the consequences of the similarity between siblings can be very different for children coming from different family backgrounds. For instance, the findings demonstrate that sibling 
correlations in upper track attendance are of a similar size for families with less and highly educated parents. However, this similarity takes place at different levels. Most children with parents with a high level of education attend the upper track in high school (Gymnasium), whereas most children from families with a low level of parental education attend one of the lower tracks. In this case, both social groups can have a similar level of sibling similarity but for very different reasons.

The question that arises is whether there is stratification in the effects of sibling characteristics on educational outcomes. It may be that children from higher-social origin families attend the upper track in any case, but that children from lowersocial origin families need favorable circumstances to do so. In that case, the factors that influence educational outcomes at the individual level and, hence, the factors that cause differences between siblings may differ between children with different socioeconomic backgrounds.

In order to test this stratification of the effects of sibling characteristics on education, I run family fixed-effects models that include interactions between sibling characteristics and parental education. These models are reported in Table 3.

Model 1 in Table 3 reveals, as expected, a negative effect of birth order on cognitive skills. On average, every increase of birth order by one position leads to a reduction in cognitive skills by 0.20 standard deviations. Hence, birth order has only a small negative effect on cognitive skills that is also not very precisely estimated. Contrary to some previous research, but in line with Barclay and Kolk (2017), I do not find any negative effect of having more closely spaced siblings on cognitive skills. The effect of maternal age is positive but substantively small in size.

In addition, there is no evidence for socioeconomic differences in the effects of sibling characteristics on cognitive skills (model 2). For all three sibling characteristics (birth order, birth spacing, and maternal age), the interactions between these sibling characteristics and parental education are statistically insignificant and also substantively close to 0 . Again, there is considerable uncertainty in the estimates. In particular, the estimate for the number of closely spaced siblings is comparably large and suggests that a negative effect of birth spacing may be concentrated in socioeconomically advantaged families. However, the estimate is too imprecisely estimated to give support that such a conclusion were to generalize to the population level. For that reason, there may be small socioeconomic differences that cannot be uncovered in the present analysis.

Models 3 and 4 in Table 3 analyze the effects of birth order, birth spacing, and maternal age on track attendance, which is arguably the most important outcome in the German education system. In particular, track attendance is most influential for future educational success (Hillmert and Jacob 2010). Model 3 finds, in line with the model for cognitive skills, positive effects of a higher maternal age and negative effects of a higher birth order on track attendance. Every increase in birth order by one position reduces the probability to attend the upper track by 6.5 percentage points. For every five-year increase in maternal age, the probability to attend the upper track is increased by 6.5 percentage points $(5 \times 0.013)$. Both effects are small, but given the importance of track attendance in the German education system, they are not negligible. These effects are only slightly smaller in size than 
Table 3: Family fixed-effects models of the effects of sibling characteristics on educational outcomes.

\begin{tabular}{|c|c|c|c|c|}
\hline & \multicolumn{2}{|c|}{$\begin{array}{c}\text { Cognitive } \\
\text { skills }^{a}\end{array}$} & \multicolumn{2}{|c|}{$\begin{array}{l}\text { Upper track } \\
\text { attendance } \\
\text { (Gymnasium) }^{b}\end{array}$} \\
\hline & (1) & (2) & (3) & $(4)$ \\
\hline Birth order & $\begin{array}{r}-0.20^{*} \\
(0.07)\end{array}$ & $\begin{array}{r}-0.22^{*} \\
(0.10)\end{array}$ & $\begin{array}{r}-0.065^{*} \\
(0.020)\end{array}$ & $\begin{array}{r}-0.094^{*} \\
(0.024)\end{array}$ \\
\hline Number of closely spaced siblings & $\begin{array}{c}-0.05 \\
(0.14)\end{array}$ & $\begin{array}{c}0.06 \\
(0.18)\end{array}$ & $\begin{array}{c}0.002 \\
(0.038)\end{array}$ & $\begin{array}{c}0.025 \\
(0.047)\end{array}$ \\
\hline Maternal age & $\begin{array}{c}0.05^{\dagger} \\
(0.03)\end{array}$ & $\begin{array}{c}0.05 \\
(0.04)\end{array}$ & $\begin{array}{c}0.013^{*} \\
(0.007)\end{array}$ & $\begin{array}{c}0.023^{*} \\
(0.007)\end{array}$ \\
\hline Male & $\begin{array}{r}0.17^{*} \\
(0.06)\end{array}$ & $\begin{array}{r}0.17^{*} \\
(0.07)\end{array}$ & $\begin{array}{r}-0.088^{*} \\
(0.019)\end{array}$ & $\begin{array}{r}-0.086^{*} \\
(0.019)\end{array}$ \\
\hline Birth order X High parental education & & $\begin{array}{c}0.03 \\
(0.14)\end{array}$ & & $\begin{array}{c}0.091^{*} \\
(0.041)\end{array}$ \\
\hline Number of closely spaced siblings $X$ High parental education & & $\begin{array}{c}-0.27 \\
(0.28)\end{array}$ & & $\begin{array}{c}-0.079 \\
(0.078)\end{array}$ \\
\hline Maternal age $X$ High parental education & & $\begin{array}{c}-0.01 \\
(0.05)\end{array}$ & & $\begin{array}{r}-0.033^{*} \\
(0.014)\end{array}$ \\
\hline$N$ & 1,327 & 1,327 & 2,671 & 2,671 \\
\hline
\end{tabular}

Notes: Cluster-robust standard errors in parentheses. Source: German Socio-Economic Panel Study (SOEP) version 32.1 (DOI: 10.5684/soepv32.1). ${ }^{a}$ OLS regression models. ${ }^{b}$ Linear probability models. ${ }^{+} p<0.10$, ${ }^{*} p<0.05$. 
A five-year decrease in maternal age in less educated families leads to a reduction in the probability of attending the upper track of 11.5 percentage points ( 5 X 0.023). This is a large negative effect of young maternal age. However, as all other estimates in this analysis, the true effect at the population level can both be smaller and larger due to the uncertainty in the estimate. The effect is, however, reversed in highly educated families in which a five-year increase in maternal age reduces (instead of increases) the probability to attend the upper track by five percentage points ( $5 \mathrm{X}$ $0.023+5 X-0.033=-0.050)$. Hence, there is no negative effect of a younger maternal age on educational attainment in highly educated families.

\section{Robustness Checks}

I tested the robustness of the result of socioeconomic differences in the effects of birth order, birth spacing, and maternal age on children's cognitive skills and track attendance by running models restricted to families with a low level of parental education and those with a high level of parental education. In addition, I used the indicators of parental occupational status and parental social class instead of parental education as alternative measures of social origin.

Table 3 in the online supplement reports the estimates of the effects of sibling characteristics on cognitive skills based on models run separately for children with parents with a high (model 1) and with a low level of education (model 2). In addition, models are estimated for children with parents with a high (model 3) and with a low level of parental occupation (model 4). Finally, separate models are estimated for children with a high (model 5) and with a low (model 6) parental social class. Findings from these models support the results obtained based on the model using the combined sample and interaction effects to estimate socioeconomic differences in effects (model 2 in Table 3). A higher birth order negatively affects children's cognitive skills, and these effects do not vary by social origin. In addition, no socioeconomic differences in the effects of close birth spacing and maternal age on cognitive skills are found. ${ }^{4}$

In addition, Table 4 in the online supplement reports models predicting attendance of the upper track run on the six subsamples. Findings of these models are fully in line with those obtained using model 4 in Table 3. A higher birth order and a younger maternal age negatively affect children's probability of attending the upper track only in families with a low level of parental education or with a low level of parental occupation. None of the three sibling characteristics affects track attendance in families with a high level of parental education or occupation.

\section{Discussion and Conclusion}

On a theoretical level, the aim of this study was to develop models of the intergenerational transmission of education that take into account socioeconomic differences in within-family processes. Empirically, I tested two ways in which within-family inequality can influence the process of educational mobility. First, I found no evidence for a variation of sibling similarity in education by family socioeconomic background in Germany. This finding is in line with the majority of educational 
outcomes analyzed by previous research using data on the United States (Conley 2008; Conley et al. 2007). This research, however, found a higher sibling similarity in socioeconomic outcomes in adulthood in the United States (Conley 2008; Conley and Glauber 2008) and in noncognitive skills in the United States (Conley et al. 2007) and in Germany (Anger and Schnitzlein 2017). I cannot estimate sibling similarity in labor market outcomes as the cohort of children I analyze is too young to have fully entered the labor market. Future research may expand on my analysis in this respect.

Second, the empirical analysis showed that the negative effects of a higher birth order and a younger maternal age on educational attainment are reduced in socioeconomically advantaged families. These findings are in line with arguments that socioeconomically advantaged parents can compensate for the negative effects of disadvantageous life events on their children's educational outcomes. Previous research obtained similar findings of a compensatory effect of social origin with respect to the negative effects of shocks in early health conditions (Almond et al. 2009), a low birth weight (Torche and Echevarría 2011), parental separation (Grätz 2015), maternal employment (Ermisch and Francesconi 2013), maternal stress (Aizer et al. 2016), and a young school entry age (Bernardi 2014; Bernardi and Grätz 2015) on child education.

The present study found a compensatory effect of a high social origin with respect to track attendance but not with respect to cognitive skills. The findings for cognitive skills are at odds with the results of Karwath et al. (2015), who reported a concentration of the negative association between birth order and children's vocabulary skills in socioeconomically disadvantaged families but did not use family fixed-effects models. Barclay (2015b), who used family fixed-effects models and Swedish register data, found, however, in line with my results, no socioeconomic differences in the effect of birth order on intelligence.

The difference between birth order and maternal age effects on cognitive skills and track attendance in my study are in line with the view that parental investments can more easily influence educational attainment than cognitive skills. This finding may be explained by the notion that the intergenerational transmission of education is largely due to socioeconomically advantaged parents influencing the educational decision making of their children, a process sometimes referred to as "secondary effects" (Boudon 1973; Jackson 2013). Another possibility, however, is that socioeconomic differences in track attendance are a result of differential parental responses that affect noncognitive but not cognitive skills. Support for the latter perspective comes from the findings of a higher sibling similarity in noncognitive skills in socioeconomically advantaged than in socioeconomically disadvantaged families (Anger and Schnitzlein 2017; Conley et al. 2007). Further research is needed to test these competing explanations of the reduced influences of birth order and maternal age on educational attainment in families with highly educated parents.

The results of this study have significance for research on educational inequalities in general. They suggest that in addition to socioeconomic differences in the occurrence of disadvantageous sibling characteristics, such as a young maternal age (McLanahan 2004), there are socioeconomic differences in the effects of birth order and maternal age on children's educational outcomes. This provides a channel 
through which what happens within families affects the intergenerational transmission of educational advantage. There are considerable differences between siblings in educational outcomes. The integration of differences within families in theories of social mobility is still an open challenge. This study, hence, underscores the need for further research on siblings. The increasing availability of data sources with information on siblings will make this a feasible enterprise. What we can hope for by using these data is to obtain a more complete understanding of the mechanisms underlying the intergenerational transmission of educational advantage.

\section{Notes}

1 Anger and Schnitzlein (2017), who also analyzed data from the German Socio-Economic Panel (SOEP), estimated variation in sibling correlations in noncognitive skills by maternal education and family income. They, did, however, not analyze socioeconomic differences in sibling similarity in cognitive skills and track attendance.

2 Some previous research estimated socioeconomic differences in the effects of some of these sibling characteristics on child education (e.g., for birth order; Black et al. 2005; Härkönen 2014; Karwath et al. 2015). With the exception of Karwath et al. (2015), who used data on a small region in Germany and had no information on siblings, these studies did not focus on analyzing socioeconomic heterogeneity. What is more, these studies did not analyze how the effects of birth order, birth spacing, and maternal age varied simultaneously by family socioeconomic background. It is, however, crucial to do so as only such an analysis provides the complete picture of how sibling characteristics influence educational mobility.

3 Given that the siblings included in the analysis were born over a period of 17 years, period effects could affect these estimates. For this reason, I reestimated all models including dummy variables for different birth cohorts. These models are reported in Tables 1 and 2 in the online supplement. They show that controlling for birth cohort does not affect the estimates of birth order, birth spacing, and maternal age effects.

4 The models splitting the sample by parental occupation find a stronger negative effect of a higher birth order and a stronger positive effect of a higher maternal age on cognitive skills for children with parents with a high level of parental occupation than for children with a low level of parental occupation. However, I believe this result should not affect the main conclusions for two reasons. First, the sample of children with parents with a high occupation used to estimate the effects of sibling characteristics on cognitive skills is very small and includes only 79 children. Second, none of the other specifications finds socioeconomic differences in the effects of birth order or maternal age on cognitive skills.

\section{References}

Aizer, Anna, Laura Stroud, and Stephen Buka. 2016. "Maternal Stress and Child Outcomes: Evidence from Siblings." Journal of Human Resources 51:523-55. https://doi .org/10. 3368/jhr.51.3.0914-6664R.

Almond, Douglas, and Bhashkar Mazumder. 2013. "Fetal Origins and Parental Responses." Annual Review of Economics 5:37-56. https://doi.org/10.1146/ annurev-economics-082912-110145. 
Almond, Douglas, Lena Edlund, and Mårten Palme. 2009. “Chernobyl's Subclinical Legacy: Prenatal Exposure to Radioactive Fallout and School Outcomes in Sweden." Quarterly Journal of Economics 124:1729-72. https://doi .org/10.1162/qjec . 2009 .124 .4 .1729.

Anger, Silke, and Daniel D. Schnitzlein. 2017. “Cognitive Skills, Non-Cognitive Skills, and Family Background: Evidence from Sibling Correlations." Journal of Population Economics 30:591-620. https: //doi .org/10.1007/s00148-016-0625-9.

Barclay, Kieron J. 2015a. "Birth Order and Educational Attainment: Evidence from Fully Adopted Sibling Groups." Intelligence 48:109-22. https: //doi .org/10.1016/j . intell. 2014.10.009.

Barclay, Kieron J. 2015b. “A Within-Family Analysis of Birth Order and Intelligence Using Population Conscription Data on Swedish Men." Intelligence 49:134-43. https: //doi . org/10.1016/j.intell.2014.12.007.

Barclay, Kieron J., and Martin Kolk. 2017. “The Long-Term Cognitive and Socioeconomic Consequences of Birth Intervals: A Within-Family Sibling Comparison Using Swedish Register Data." Demography 54:459-84. https://doi .org/10.1007/s13524-017-0550-x.

Barclay, Kieron J., and Mikko Myrskylä. 2016. “Advanced Maternal Age and Offspring Outcomes: Reproductive Aging and Counterbalancing Period Trends." Population and Development Review 42:69-94. https : //doi .org/10.1111/j .1728-4457.2016.00105.x.

Becker, Gary S. 1991. A Treatise on the Family. Enlarged Edition. Cambridge, MA: Harvard University Press.

Becker, Gary S., and Nigel Tomes. 1976. "Child Endowments and the Quantity and Quality of Children." Journal of Political Economy 84:S143-62. https://doi .org/10.1086/260536.

Behrman, Jere R., Robert A. Pollak, and Paul Taubman. 1982. "Parental Preferences and Provision for Progeny." Journal of Political Economy 90:52-73. https ://doi .org/10. 1086/ 261039.

Benin, Mary H., and David R. Johnson. 1984. "Sibling Similarities in Educational Attainment: A Comparison of Like-Sex and Cross-Sex Sibling Pairs." Sociology of Education 57:11-21.

Bernardi, Fabrizio. 2014. “Compensatory Advantage as a Mechanism of Educational Inequality: A Regression Discontinuity Based on Month of Birth." Sociology of Education 87:74-88.

Bernardi, Fabrizio, and Michael Grätz. 2015. “Making Up for an Unlucky Month of Birth in School: Causal Evidence on the Compensatory Advantage of Family Background in England." Sociological Science 2:235-51. https: //doi .org/10.15195/v2 . a12.

Bjerkedal, Tor, Petter Kristensen, Geir A. Skjeret, and John I. Brevik. 2007. "Intelligence Test Scores and Birth Order Among Young Norwegian Men (Conscripts) Analyzed Within and Between Families." Intelligence 35:503-14. https://doi.org/10.1016/j.intell. 2007.01 .004$.

Björklund, Anders, and Kjell G. Salvanes. 2011. “Education and Family Background: Mechanisms and Policies." Pp. 201-47 in Handbook of the Economics of Education, Vol. 3, edited by E. A. Hanushek, S. Machin, and L. Woessmann. Amsterdam, Netherlands: Elsevier. https://doi.org/10.1016/B978-0-444-53429-3.00003-X.

Björklund, Anders, and Markus Jäntti. 2012. "How Important is Family Background for Labor-Economic Outcomes?" Labour Economics 19:465-74. https://doi .org/10.1016/j. labeco.2012.05.016.

Black, Sandra E., Paul J. Devereux, and Kjell G. Salvanes. 2005. “The More, the Merrier? The Effect of Family Size and Birth Order on Children's Education." Quarterly Journal of Economics 120:669-770. 
Booth, Alison L., and Hiau Joo Kee. 2009. "Birth Order Matters: The Effect of Family Size and Birth Order on Educational Attainment." Journal of Population Economics 22:367-97. https://doi .org/10.1007/s00148-007-0181-4.

Boudon, Raymond. 1973. L'Inégalité des Chances. Paris, France: Armand Colin.

Breen, Richard, and Jan O. Jonsson. 2005. "Inequality of Opportunity in Comparative Perspective: Recent Research on Educational Attainment and Social Mobility." Annual Review of Sociology 31:223-43. https://doi .org/10.1146/annurev . soc. 31.041304.122232.

Buckles, Kasey S., and Elizabeth L. Munnich. 2012. "Birth Spacing and Sibling Outcomes." Journal of Human Resources 47:613-42. https: //doi .org/10.3368/jhr .47.3.613.

Conley, Dalton. 2004. The Pecking Order: Which Siblings Succeed and Why. New York, NY: Pantheon Books.

Conley, Dalton. 2008. “Bringing Sibling Differences In: Enlarging Our Understanding of the Transmission of Advantage in Families." Pp. 179-200 in Social Class: How Does It Work?, edited by A. Lareau and D. Conley. New York, NY: Russell Sage Foundation.

Conley, Dalton, and Rebecca Glauber. 2008. "All in the Family? Family Composition, Resources, and Sibling Similarity in Socioeconomic Status." Research in Social Stratification and Mobility 26:297-306. https://doi .org/10.1016/j.rssm.2008.08.003.

Conley, Dalton, Kathryn M. Pfeiffer, and Melissa Velez. 2007. “Explaining Sibling Differences in Achievement and Behavioral Outcomes: The Importance of Within- and Between-Family Factors." Social Science Research 36:1087-104. https://doi .org/10. 1016/j.ssresearch.2006.09.002.

de Graaf, Paul, and Johannes Huinink. 1992. “Trends in Measured and Unmeasured Effects of Family Background on Educational Attainment and Occupational Status in the Federal Republic of Germany." Social Science Research 21:84-112. https://doi.org/10.1016/ 0049-089X (92) 90019-D.

Duncan, Greg J., Johanne Boisjoly, and Kathleen M. Harris. 2001. “Sibling, Peer, Neighbor, and Schoolmate Correlations as Indicators of the Importance of Context for Adolescent Development." Demography 38:437-47. https ://doi .org/10.1353/dem.2001.0026.

Ermisch, John, and Marco Francesconi. 2013. "The Effect of Parental Employment on Child Schooling." Journal of Applied Econometrics 28:796-822. https://doi .org/10.1002/jae . 2260.

Erola, Jani, and Elina Kilpi-Jakonen. 2017. "Compensation and Other Forms of Accumulation in Intergenerational Social Inequality." Pp. 3-25 in Social Inequality Across the Generations: The Role of Compensation and Multiplication in Resource Accumulation, edited by J. Erola and E. Kilpi-Jakonen. Cheltenham, United Kingdom: Edward Elgar. https://doi .org/10. 4337/9781786432568.00006.

Esping-Andersen, Gøsta. 1990. The Three Worlds of Welfare Capitalism. Princeton, NJ: Princeton University Press.

Frisell, Thomas, Sara Öberg, Ralf Kuja-Halkola, and Arvid Sjölander. 2012. "Sibling Comparison Designs: Bias from Non-Shared Confounders and Measurement Error." Epidemiology 23:713-20.

Ganzeboom, Harry B. G., Paul M. de Graaf, and Donald J. Treiman. 1992. "A Standard International Socio-Economic Index of Occupational Status." Social Science Research 21:1-56. https ://doi .org/10.1016/0049-089X (92)90017-B.

Grätz, Michael. 2015. "When Growing Up Without a Parent Does Not Hurt: Parental Separation and the Compensatory Effect of Social Origin." European Sociological Review 31:546-57. https://doi.org/10.1093/esr/jcv057. 
Grätz, Michael, and Florencia Torche. 2016. “Compensation or Reinforcement? The Stratification of Parental Responses to Children's Early Ability." Demography 53:1883-904. https://doi.org/10.1007/s13524-016-0527-1.

Griliches, Zvi. 1979. "Sibling Models and Data in Economics: Beginning of a Survey." Journal of Population Economics 87:S37-64. https ://doi .org/10.1086/260822.

Hauser, Robert M., and Peter A. Mossel. 1985. "Fraternal Resemblance in Educational Attainment and Occupational Status." American Journal of Sociology 91:650-73. https: //doi.org/10.1086/228317.

Hauser, Robert M., and Raymond S.-K. Wong. 1989. "Sibling Resemblance and Intersibling Effects in Educational Attainment." Sociology of Education 62:149-71. https : //doi .org/ $10.2307 / 2112864$.

Härkönen, Juho. 2014. “Birth Order Effects on Educational Attainment and Educational Transitions in West Germany." European Sociological Review 30:166-79. https ://doi .org/ 10.1093/esr/jct027.

Hillmert, Steffen, and Marita Jacob. 2010. "Selections and Social Selectivity on the Academic Track: A Life Course Analysis of Educational Attainment in Germany." Research in Social Stratification and Mobility 28:59-76. https://doi .org/10.1016/j .rssm.2009.12.006.

Hsin, Amy. 2012. "Is Biology Destiny? Birth Weight and Differential Parental Treatment." Demography 49:1385-404. https : //doi .org/10.1007/s13524-012-0123-y.

Jackson, M., ed. 2013. Determined to Succeed? Performance versus Choice in Educational Attainment. Stanford, CA: Stanford University Press. https://doi .org/10.11126/stanford/ 9780804783026.001 .0001$.

Jencks, Christopher, Marshall Smith, Henry Acland, Mary Jo Bane, David Cohen, Herbert Gintis, Barbara Heyns, and Stephan Michelson. 1972. Inequality: A Reassessment of the Effect of Family and Schooling in America. New York, NY: Basic Books.

Kalmijn, Matthijs, and Gerbert Kraaykamp. 2005. "Late or Later? A Sibling Analysis of the Effect of Maternal Age on Children's Schooling." Social Science Research 34:634-50. https://doi.org/10.1016/j.ssresearch.2004.04.008.

Kantarevic, Jasmin, and Stéphane Mechoulan. 2006. "Birth Order, Educational Attainment, and Earnings: An Investigation using the PSID." Journal of Human Resources 41:755-77. https://doi.org/10.3368/jhr.XLI.4.755.

Karwath, Claudia, Ilona Relikowski, and Monja Schmitt. 2015. "Sibling Structure and Educational Achievement: How do the Number of Siblings, Birth Order, and Birth Spacing Affect Children's Vocabulary Competences." Zeitschrift für Familienforschung 26:372-96.

Kristensen, Petter, and Tor Bjerkedal. 2007. "Explaining the Relation between Birth Order and Intelligence." Science 316:1717. https://doi.org/10.1126/science.1141493.

Kristensen, Petter, and Tor Bjerkedal. 2010. "Educational Attainment of 25 Year Old Norwegians according to Birth Order and Gender." Intelligence 38:123-36. https: //doi.org/10.1016/j.intell.2009.08.003.

Kuo, Hsiang-Hui D., and Robert M. Hauser. 1995. "Trends in Family Effects on the Education of Black and White Brothers." Sociology of Education 68:136-60. https://doi.org/10. $2307 / 2112779$.

Mare, Robert D., and Meei-Sheen Tzeng. 1989. "Fathers' Ages and the Social Stratification of Sons." American Journal of Sociology 95:108-31. https: //doi .org/10.1086/229215.

Mazumder, Bhashkar. 2008. "Sibling Similarities and Economic Inequality in the US." Journal of Population Economics 21:685-701. https : //doi .org/10.1007/s00148-006-0127-2. 
McLanahan, Sara. 2004. "Diverging Destinies: How Children Are Faring Under the Second Demographic Transition." Demography 41:607-27. https: //doi .org/10.1353/dem. 2004. 0033.

Mood, Carina. 2010. "Logistic Regression: Why We Cannot Do What We Think We Can Do, and What We Can Do About It." European Sociological Review 26:67-82. https: //doi.org/10.1093/esr/jcp006.

Nicoletti, Cheti, and Birgitta Rabe. 2013. “Inequality in Pupils' Test Scores: How Much do Family, Sibling Type and Neigbourhood Matter?" Economica 80:197-218. https: //doi.org/10.1111/ecca.12010.

Olneck, Michael R. 1977. “On the Use of Sibling Data to Estimate the Effects of Family Background, Cognitive Skills, and Schooling: Results from the Kalamazoo Brothers Study." Pp. 125-62 in Kinometrics: Determination of Socioeconomic Success Within and Between Families, edited by P. Taubman. Amsterdam, Netherlands: North-Holland Publishing Company.

Pettersson-Lidbom, Per, and Peter Skogman Thoursie. 2009. “Does Child Spacing Affect Children's Outcomes? Evidence from a Swedish Reform." Working Paper No. 2009-7, Institute for Evaluation of Labour Market and Educational Policy.

Pfeffer, Fabian T. 2008. "Persistent Inequality in Educational Attainment and its Institutional Context." European Sociological Review 24:543-65. https: //doi .org/10.1093/esr/ jen026.

Powell, Brian, and Lala Carr Steelman. 1990. "Beyond Sibship Size: Sibling Density, Sex Composition, and Educational Outcomes." Social Forces 69:181-206. https : //doi .org/ 10.1093/sf/69.1.181.

Powell, Brian, and Lala Carr Steelman. 1993. “The Educational Benefits of Being Spaced Out: Sibship Density and Educational Progress." American Sociological Review 58:367-81. https://doi.org/10.2307/2095906.

Powell, Brian, and Lala Carr Steelman. 1995. "Feeling the Pinch: Age Spacing and Economic Investments in Children." Social Forces 73:1465-86. https://doi .org/10.1093/sf/73.4. 1465.

Powell, Brian, Lala Carr Steelman, and Robert M. Carini. 2006. “Advancing Age, Advantaged Youth: Parental Age and the Transmission of Resources to Children." Social Forces 84:135990. https://doi.org/10.1353/sof .2006.0064.

Price, Joseph. 2008. "Parent-Child Quality Time: Does Birth Order Matter?" Journal of Human Resources 43:240-63. https://doi .org/10.3368/jhr.43.1.240.

Restrepo, Brandon J. 2016. "Parental Investment Responses to a Low Birth Weight Outcome: Who Compensates and who Reinforces?" Journal of Population Economics 29:969-89. https://doi.org/10.1007/s00148-016-0590-3.

Schnitzlein, Daniel D. 2014. "How Important is the Family? Evidence from Sibling Correlations in Permanent Earnings in the US, Germany and Denmark." Journal of Population Economics 27:69-89. https://doi.org/10.1007/s00148-013-0468-6.

Schulze, Alexander, and Peter Preisendörfer. 2013. “Bildungserfolg von Kindern in Abhängigkeit von der Stellung in der Geschwisterreihe." Kölner Zeitschrift für Soziologie und Sozialpsychologie 65:339-56. https://doi.org/10.1007/s11577-013-0205-x.

Schupp, Jürgen, and Sabrina Herrmann. 2009. Kognitionspotentiale Jugendlicher: Ergänzung zum Jugendfragebogen der Längsschnittstudie Sozio-oekonomisches Panel (SOEP). Berlin, Germany: German Institute for Economic Research.

Shavit, Yossi, and Hans-Peter Blossfeld, eds. 1993. Persistent Inequality: Changing Educational Attainment in Thirteen Countries. Boulder, CO: Westview Press. 
Sieben, Inge, and Paul de Graaf. 2001. "Testing the Modernization Hypothesis and the Socialist Ideology Hypothesis: A Comparative Sibling Analysis of Educational Attainment and Occupational Status." British Journal of Sociology 52:441-67. https: //doi.org/10.1080/00071310120071133.

Sieben, Inge, and Paul de Graaf. 2003. "The Total Impact of the Family on Educational Attainment." European Societies 5:33-68. https://doi.org/10.1080/1461669032000057668a.

Sieben, Inge, Johannes Huinink, and Paul de Graaf. 2001. “Family Background and Sibling Resemblance in Educational Attainment: Trends in the Former FRG, the Former GDR and the Netherlands." European Sociological Review 17:401-30. https://doi .org/10.1093/ esr/17.4.401.

SOEP. 2017. Socio-Economic Panel (SOEP), Data for Years 1984-2015, Version 32.1. https://dx.doi.org/doi:10.5684/soep.v32.1.

Stoye, Kristian. 2016. Bildungschancen im Spiegel familiendemografischer Veränderungen: Der Einfluss von Geschwister- und Familienkonstellationen. Wiesbaden, Germany: Springer VS. https://doi.org/10.1007/978-3-658-13608-6.

Teachman, Jay D. 1995. "Sibling Resemblance and Symmetry in Intellectual Skill." Sociology of Education 68:205-20. https : //doi .org/10.2307/2112685.

Toka, Gabor, and Jaap Dronkers. 1996. "Sibling Resemblance in Educational Attainment, Occupational Prestige, and Wealth in Hungary during the Communist Regime." European Sociological Review 12:251-69. https : //doi .org/10.1093/oxfordjournals . esr . a018191.

Torche, Florenica, and Ghislaine Echevarría. 2011. “The Effect of Birthweight on Childhood Cognitive Development in a Middle-Income Country." International Journal of Epidemiology 40:1008-18. https://doi.org/10.1093/ije/dyr030.

van Eijck, Koen, and Paul M. de Graaf. 1995. “The Effects of Family Structure on the Educational Attainment of Siblings in Hungary." European Sociological Review 11:273-92. https://doi.org/10.1093/oxfordjournals.esr.a036364.

Wagner, Gert G., Joachim R. Frick, and Jürgen Schupp. 2007. "The German Socio-Economic Panel Study (SOEP): Scope, Evolution and Enhancements." Schmollers Jahrbuch (Journal of Applied Social Science Studies) 127:139-69. https : //doi .org/10.2139/ssrn.1028709.

Acknowledgements: I thank the German Academic Exchange Service (DAAD) for supporting my research through a PhD scholarship. The research leading to these results has received funding from the European Union's Seventh Framework Programme (FP7/2007-2013) under grant agreement no. 320116 for the research project FamiliesAndSocieties. Earlier versions of this article were presented at the European Consortium for Sociological Research conference in Tilburg, the annual meeting of the Population Association of America in Boston, the ISA RC28 on Social Stratification and Mobility meeting in Budapest, the SOEP User Conference in Berlin, and at workshops in Zürich and Berlin. For their helpful suggestions on earlier drafts of this manuscript, I would like to thank Tina Baier, Fabrizio Bernardi, Diederik Boertien, Andrés Cardona, Dalton Conley, Juho Härkönen, Anne Christine Holtmann, and Florencia Torche.

Michael Grätz: Nuffield College, University of Oxford; Faculty of Sociology, Bielefeld University. E-mail: michael.gratz@nuffield.ox.ac.uk. 